\title{
Conditions for disarmament
}

SIR - J.N. Barkenbus and A.M. Weinberg (Nature 310, 95; 1984) were right to object that Stephen Salter's proposal for a superpowers disarmament negotiations algorithm $(308,490 ; 1984)$ assumes an unrealistic degree of collaboration between the protagonists. But it may slightly misleading to term the Salter scheme "original". Undoubtedly it is $\mathrm{Mr}$ Salter's own autonomous creation, and in its particular form it may also be entirely novel. It is certainly both elegant and economically structured. However, the "I cut - you choose" algorithm was suggested for this purpose in an article in Journal of Conflict Resolution 1963 by E. Singer.

The many differences between the Singer and Salter versions of what the former terms the "divide and choose" approach are probably of little interest, except to those who set more store by the contemplation of abstract negotiation models than I do. Suffice it to notice here that Singer's approach was to place all weapon retentions and weapon discards by both sides into a single population to be divided, and then to consider solutions to the difficulties this could pose. He also throws out the interesting suggestion that on-site inspection rights could be bargained for in the same or another similar structure, after they had first been portioned out in territorial units.

Unlike Salter, Singer did not so much see his scheme as replacing the antagonistic conduct of international relations, but rather as having to take its chances within the sordid arena of diplomacy. Thus he concludes: "Eventually, the realities of international negotiations must be confronted, and the diplomatic foxes must be set free to see if they can, without too much difficulty, play havoc with a bargaining model".

It is a pity that Barkenbus and Weinberg were unable to espouse the realism whose absence they regret in Salter. For it is certainly very naive to suppose, as their model does, that the arms race is about preserving a stable parity between the deliverable portions of populations of militarily undifferentiated "warheads". Their second and probably related assumption, also hard to share, is that we are dealing always and only with retaliatory forces. For once the idea of an attempted disarming first strike is admitted into the strategic calculations (as it always has been on both sides), it is no longer possible to claim that erection of a defensive anti-missile system can be directly offset by dismantling a proportion of one's own offensive missiles, to match the proportion of an enemy missile strike one expects to be able to block. For suppose Side A, with its new defensive system and, say, a matching 10 per cent reduction of offensive forces, were now to initiate a strategic first strike. The 90 per cent offensive force would be virtually as effective as before the reduction, and the defensive force, facing only the decimated and disrupted remains of B's strategic offensive capability, would be very much more than 10 per cent effective because it would be handling a much smaller salvo of incoming warheads.

Since this is the worst-case scenario which would govern B's perceptions of A's new defensive deployment, it could be argued that the latter should be offset by a reduction of A's offensive arsenal proportional to the hypothetical "thinning" by which B's offensive forces would receive by the two processes of, first, an attempted disarming first strike by $\mathbf{A}$, and second, the anti-missile effects of A's defences on B's subsequent retaliation. Thus A would have to pay for its 10 per cent effective defences with, say, an 80 per cent reduction of its offensive forces.

But of course A could not accept this, because it has to see the world as one in which $\mathrm{B}$ could be making the first strike, which demonstrates that there is no way to provide a "fair" mix of offensive and defensive deployments, except by making artificial and unrealistic assumptions to the effect that all nuclear strikes will always be retaliations, which is of course a useless option, despite Barkenbus and Weinberg's so boldly having taken it. R.I.P. BULKELEY Department of War Studies,

Kings College London,

Strand, London WC2R $2 L S, U K$

SIR - The leading article "Targets for future arms control" (18 October, p.591) was both pessimistic and realistic. In a climate of mutual and reciprocal suspicion between the nuclear armed states, perhaps we should look to small, but achievable, measures that both build confidence and reduce further escalation of the nuclear arms race. I propose a measure that might achieve this and at the same time bolster the Non-Proliferation Treaty (NPT), which, you rightly comment, mercifully still holds, but only tenuously.

With 50,000 or so nuclear warheads worldwide, there is surely no need to add to this total. If so, then an effective "freeze" on fissile material production should be agreed to and implemented by each of the nuclear weapon states. A partial freeze of this sort was agreed by the US, UK and Soviet governments in April 1964.

In order to implement this, the nuclear weapon states would have to open up their reprocessing plants and plutonium/ enriched uranium stockpiles to full inspection by a supra-national agency.

In his book Face the Future (1981, pp. 488-89), former British Foreign Secretary Dr David Owen has already argued this, basing his conclusions on his experience in office. With the Soviet Union recently accepting International Atomic Energy Agency (IAEA) safeguarding on some of its civil nuclear facilities and with the People's Republic of China joining IAEA, the foundations of progress exist.

The French and British dual-purpose nuclear facilities, such as Marcoule and Phénix, and Sellafield remain a problem. Indeed Dr D. G. Avery, appearing on behalf of British Nuclear Fuels PLC, told the Sizewell B Inquiry (16 October) that the British Government and Euratom have been at loggerheads since 1973 over the non-accessibility of the Sellafield reprocessing line to physical inspection, despite Britain's accession to the Euratom treaty as a full partner.

Nonetheless, this problem certainly seems surmountable. This being so, it would surely strengthen the NPT, whose review conference in September 1985 is surely going to demand more equitable behaviour by the nuclear weapon states if others are not to withdraw, with the disastrous consequence of a nuclear free-forall.

Energy Research Group,

Open University, Walton Hall, Milton Keynes MK7 6AA, UK

\section{Family planning}

SIR - The reduction of the birth rate in China by one-half during the 1970s, reported in Nature $(310,612 ; 1984)$, is indeed welcome news. In view of high levels of fertility persisting in many areas of the world $^{1}$, what are the prospects for this feat to be duplicated elsewhere?

The primary requirement for a successful population programme must surely be the participation of most of the population in the programme; yet even in campaigns as vigorous as that in India, fewer than 1 in 4 eligible couples are protected ${ }^{2}$. So the choice of method may be of secondary importance - pills and rhythm, for example, seem to have a similar overall impact on the fertility of acceptors ${ }^{3}$.

How can the scope of population programmes be broadened in societies which are less highly centralized than China's? A mass-marketing approach may be effective, as demonstrated by the unfortunate popularity of artificial infant feeding formulas in even the poorest areas. A more beneficial twist of this technique might involve the use of some other highly marketable health product in conjunction with a family planning campaign. Due to the threat of anaemia (see for example Nature 310, 615; 1984), iron supplements would be beneficial and would have a high level of appeal to women. By distributing supplements in packets of 28 and colourcoding them for the safe and unsafe days of the menstrual cycle, for example, many more women might be introduced to the practice of family planning than have been reached by conventional programmes.

STEVEN L. MARCUS

Department of Atmospheric Sciences, University of California, Los Angeles, Los Angeles, California 90024, USA 1. McNamata, R.S. Foreign Affairs 62, 1107-1131 (1984) . Basu, A. M. Stud. Fam. Plann, 15, 136-142 (1984). Laing, J. E. Stud. Fom. Plann. 15, 49-61 (1984). 